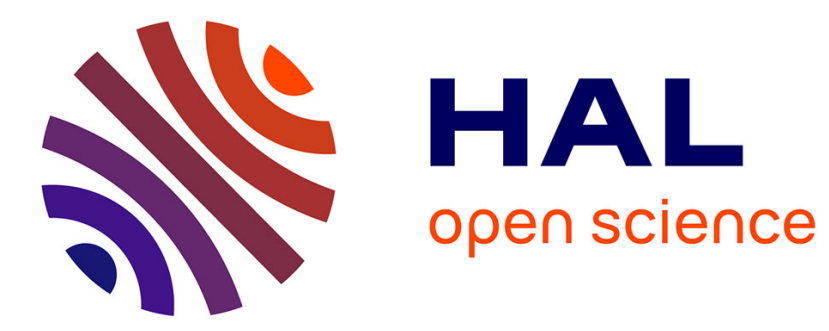

\title{
Sliding contacts on printed circuit boards and wear behavior
}

\author{
J.-P. Le Solleu
}

\section{To cite this version:}

J.-P. Le Solleu. Sliding contacts on printed circuit boards and wear behavior. European Physical Journal: Applied Physics, 2010, 50 (1), pp.12902. 10.1051/epjap/2010020 . hal-00581869

\section{HAL Id: hal-00581869 \\ https://hal.science/hal-00581869}

Submitted on 1 Apr 2011

HAL is a multi-disciplinary open access archive for the deposit and dissemination of scientific research documents, whether they are published or not. The documents may come from teaching and research institutions in France or abroad, or from public or private research centers.
L'archive ouverte pluridisciplinaire HAL, est destinée au dépôt et à la diffusion de documents scientifiques de niveau recherche, publiés ou non, émanant des établissements d'enseignement et de recherche français ou étrangers, des laboratoires publics ou privés. 


\title{
Sliding contacts on Printed Circuit Boards and wear behavior
}

\author{
Jean-Pierre LE SOLLEU
}

Delphi Controls and Security, BP90332 67411 Illkirch, France

jean.pierre.lesolleu@delphi.com

\begin{abstract}
Abstarct
Automotive suppliers use since decades Printed Circuit Boards (PCB) gold plating pads, as direct contact interface for low current sliding contacts.

Several Gold plating processes are available on the market, providing various wear behaviour. Some specific galvanic hard gold ${ }^{1}$ plating was developed on PCB's. This specific plating generates extra costs due to the material quantity and also the process complexity.

In a cost driven industry, the challenge is to use a standard low cost PCB for systems requesting high reliability performances.

After a brief overview of standard PCB manufacturing processes and especially Gold plating processes, the global experimental results of wear behaviour of three different gold plating technologies will be exposed and an explanation of the correlation between surface key parameters and wear out will be provided.
\end{abstract}

\section{Key words:}

Sliding - wear -PCB - flash gold - roughness

\section{Introduction}

When using PCB gold pads as static contact interface for sliding contact applications, we observed significant differences on wear behavior depending mainly on the type of Nickel / Gold plating used on the PCB.

Three major technologies of Gold contact surfaces on PCB are mainly used and will be considered in this study.

- Galvanic Hard Gold electroplating

- Electroless Nickel Immersion Gold (ENIG)

- Electrolytic pattern flash gold

Hard Gold plating is a reference in term of performance and contact reliability for low current applications, but it is also the most expensive technology. Flash Gold technologies presents a real cost interest.

As wear is the key driver for reliability of sliding contacts, the major focus of this study is given on the wear behaviour of different PCB technologies, in order to be able to quantify the contact performances during lifetime.

Based on lifetime tests results, we could observe some significant wear differences between the three above mentioned gold plating technologies, depending mainly on the type of stationary contact surface.

The results presented in this paper are based on tests and analysis conducted on ENIG, Electrolytic flash Gold and galvanic hard gold printed circuit boards using the same contact slider for each test. A short overview of a typical wear failure with a $2 \mu \mathrm{m}$ Hard Gold application will be presented.

The contact sliders used in this study (See Fig. 1) are standard bronze based contact spring, which are electroplated with a Nickel underlayer and a Gold Cobalt layer. The contact geometry is spherical with a radius at $0.9 \mathrm{~mm}$. The contact force is set up at $0.35 \mathrm{~N}$.

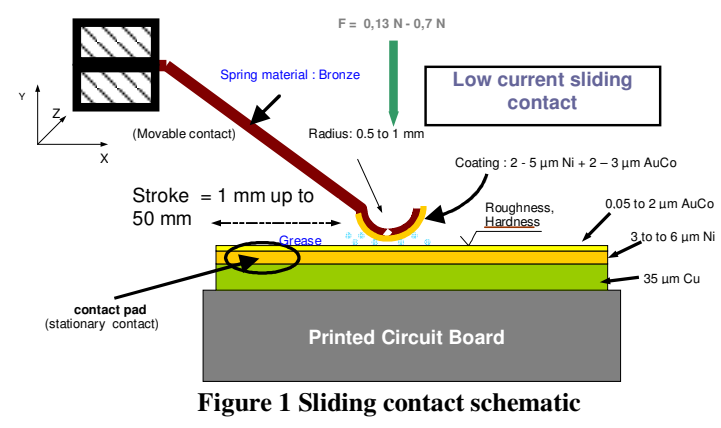

\section{Usual gold plating types on PCB}

\subsection{Galvanic Hard Gold}

Hard Gold is used where either a very resilient surface finish is required, or in the case of sliding applications or edge connectors, where a wear resistant and oxide free finish is required.

\footnotetext{
${ }^{1} \mathrm{AuCo}$ or $\mathrm{AuNi}$
} 
Unlike electroless finishes being an electrolytic process an electric current is required to plate the gold onto the board. The thickness of the gold coating can be easily controlled by the plating current (density) and plating time. In the days of old, edge connectors were regularly specified as requiring 7.5 microns of gold plating, our sliding applications normally plates 2 microns. To plate a sliding pad, a panel is normally masked with tape of peelable resist, and then dipped into the plating solution. As the pads to be plated needs to be electrically connected to the same potential or electrode, special connection feeders are necessary. Those feeders have to be removed by etching or mechanical cutting when possible.

\subsection{Flash gold}

The flash gold PCB is designed to provide an oxidization / corrosion protection of the pads to ensure a safe soldering of the electronic components. It is initially not designed as a contact interface.

Due to the very low thickness of gold (25 to $100 \mathrm{~nm}$ ), Gold flash is not sufficient to provide long term reliable contact resistance without additional protection.

Any flash is porous, and exhibits the underneath Nickel layer through the pores, this can generate an oxide and increase the contact resistance.

To avoid corrosion or oxidization of the Nickel, a contact grease with specific protection properties (perfluor polyester base) is used.

Two standard processes are used to obtain a gold flash; Electroless Nickel Immersion Gold (ENIG) and electrolytic pattern plating.

\subsubsection{Electroless Nickel Immersion Gold (ENIG)}

The electroless nickel is an auto-catalytic process depositing nickel on the palladium catalyzed copper surface. The reducing agent containing nickel ions must be replenished in order to provide proper concentration, temperature and $\mathrm{pH}$ levels necessary for this step in the ENIG process in order to create a consistent coating. The nickel is then processes with the gold, or a better description would be that the gold applies it-self to the nickel plated areas to protect the nickel until the soldering process. The gold thickness needs to meet tolerances to ensure that the nickel maintains its solderability.

\subsubsection{Electrolytic Pattern Plating}

A negative image of the pattern is first formed on the surface of the copper, using an appropriate photoresist. Gold is then electroplated to the required thickness all across the exposed areas of the pattern. The photoresist is stripped off in the next step, and finally the background copper etched off to define the circuit, using the plated gold as an etch resist. Though copper etchants do not attack gold, there is enhanced reaction in the vicinity of the gold-copper interface as a result of electrochemical potential between the two elements. This causes severe undercutting of the edges, and an undesirable gold foil overhang is formed as shown in Fig. 2. During subsequent cleaning and other handling of the circuit, this overhang could fold down the edges or sometimes fall off as small slivers. There is no effective way to remove the unwanted gold completely, and that has an obvious influence on the edge resolution of the finished circuit. Special chemistry and etching methods are under investigation to minimize these effects. By careful control it is currently possible to limit the gold overhang to about $0.5 \mathrm{mil}^{2}$ per edge.

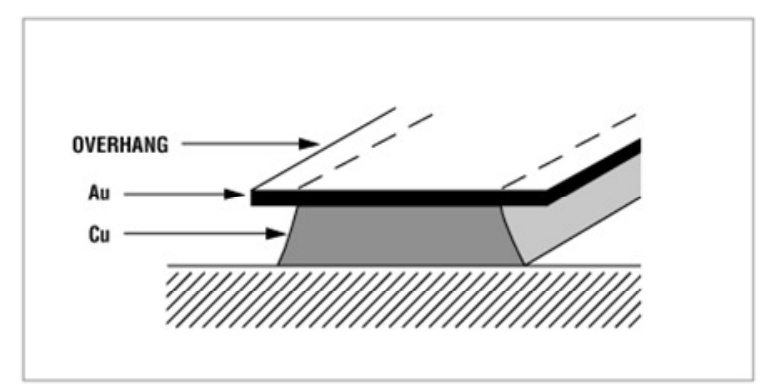

Figure 2 Nickel \& Gold overhang on electrolytic pattern plating

By comparing the wear of the blade crossing the edge and the blade on a continuous pad, no significant impact on wear could be demonstrated. The overhang is controlled and measured by the etch factor ${ }^{3}$.

Major risk is copper oxidization and electro migration as the copper edge is not protected, grease will provide an additional protection against electro migration

\section{Key parameters driving wear}

\subsection{On hard gold contact pads}

With a $2 \mu \mathrm{m}$ thick hard gold (AuNi or AuCo) layer on the contact pad the hardness values of both sliding partners are in the same range and wear is quite balanced between static contact surface and movable contact. Variations are mainly driven by process variations.

When the gold thickness is sufficient, the roughness has less influence, even hard gold will run in with the first pass of the blade. The influence of the gold thickness on wear was not quantified during this study and raises the question; at which minimum gold thickness will the Nickel roughness becomes the preponderant factor on blade wear?

\footnotetext{
${ }^{2} 1 \mathrm{mil}=1$ milli-inch $=25,4 \mu \mathrm{m}$

${ }^{3}$ Etch factor is defined in standard IPC A-600 §
} 
Another key factor to consider for the hard gold layer on PCB is the metallic deposit homogeneity.

A Printed Circuit Board sample exhibiting accelerated wear, on which hardness, thickness and roughness of gold were conform to specified values, was analyzed by generating a scratch with a nano indenter on the Nickel / Gold layer. The sanning electron microscope picture of the generated scratch (Fig. 3) shows:

- Micro cracks. See arrow (a) on the picture

- Non adhesive debris (like flakes on the edge of the scratch) spread on the surface. Arrow (b) on the picture

- Some black dots embedded in the Gold layer, arrows (c)

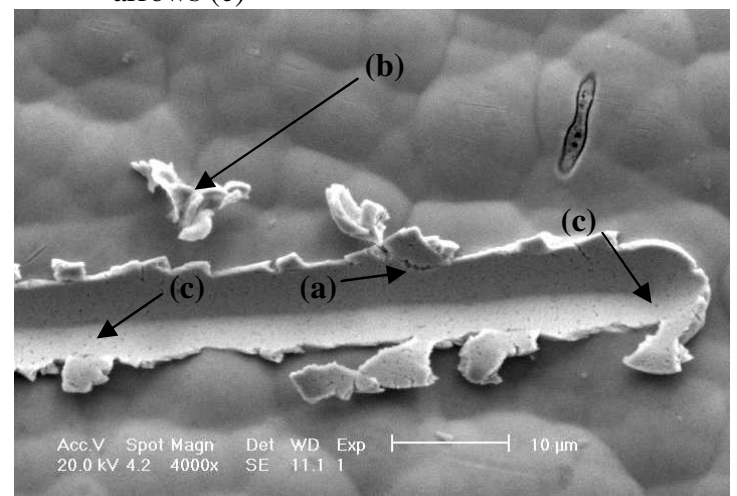

Figure 3 Scratch generated with nano indenter under controlled load

During the displacement of the indenter generating the scratch, both tangential and longitudinal forces are recorded and displayed on the diagram shown in Fig. 4. When comparing two boards, the first one exhibiting accelerated wear (squared dots), the second one producing "normal" or acceptable wear (triangles), we can see on the plot of Fig 4 that the tangential force of the first board exhibits high discontinuity (erratic curve) whereas the tangential force of the second board follows a more continuous slope as normal force increases. Those discontinuities in tangential force on first sample reflect the non homogeneity of the layer and the formation of micro cracks and wear debris.

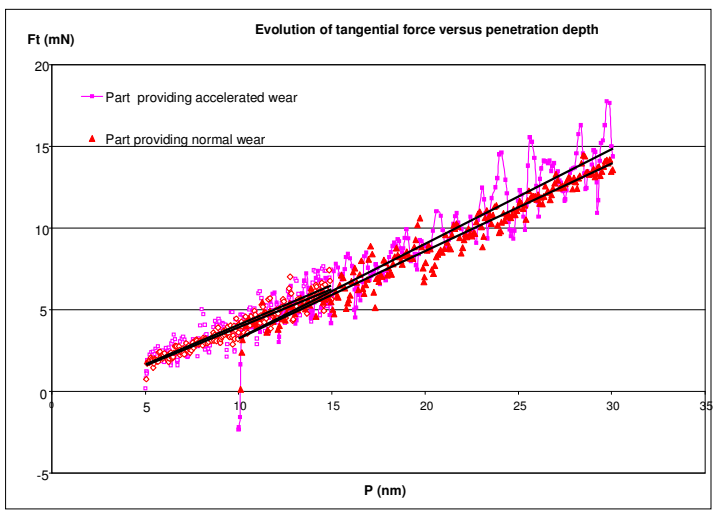

Figure 4 Tangential force evolution during scratch generation
A Scanning Electron Microscope Edx material analysis inside the generated furrow in the gold layer could show that the black dots composition is mainly organic. Some deeper investigations of the gold deposit process and especially the analysis of the gold bath chemicals allowed us to link those black dots to the organic contamination of the gold bath. This example shows the particular sensitivity of PCB towards organic contamination. During the Nickel and gold plating process steps the whole laminate including photoresist films and polymers are immersed in the electrolyte, due to the nature of those components, it is easy to understand that if the electrolyte carbon filtration is not efficient, such organic contamination can occur and generate mechanical wear issues.

\subsection{On flash gold contact pads}

\subsubsection{Grease}

In our case the grease is chosen in order to provide a good oxidization protection and allow the contact functionality at temperatures down to $-40^{\circ} \mathrm{C}$.

This protection is validated with specific thermal \& humidity cycling, acid aqueous solution aspersion, and 4 Gaz corrosion test ${ }^{4}$.

Detailed results are not presented in this paper; we will provide some global observations and additional questioning.

Based on lifetime tests and wear observations on the sliding blade, we could find out that depending on the PCB surface roughness, the mixture of grease and hard metallic wear debris could in some case accelerate the wear. When using grease in a sliding contact, the roughness of the hardest partner has to be maintained bellow a certain value and kept under control. This value is determined experimentally with abrasion measurements during lifetime tests.

In best case we observed an abrasion improvement due to the grease from nearly $10 \%$.

The grease can also provides negative effects by increasing the contact bouncing time and the minimum contact force due to an increased film resistance. The grease is an insulating layer in the contact interface, with a certain viscosity (base oil) and flow pressure. It has been demonstrated that grease always increases the minimum contact force that is needed to establish a stable contact. The necessary pressure to press down the film present in the contact interface and provide the constriction resistance only, is higher on a lubricated contact compared to a dry, non corroded contact.

Electrical contact bounce occurs in most switching contacts. In the general case, when two objects collide, there is inevitably a mechanical rebound. In the case of electrical contacts each bounce becomes a very fast make and break operation, what we call a "contact bouncing". As the grease has a certain viscosity, it influences the dynamic switching phase by increasing

\footnotetext{
${ }^{4}$ IEC 68 Methods $3 \& 4$
} 
the contact bouncing time which is the necessary time to stabilize the contact during the transient switching phase. The presence of non conductive particles (especially with PTFE based greases) is also a potential risk for the contact instability that is under investigation. The effect of grease on the contact resistance was not measured in this study as it was considered as "acceptable" by the switched system, even with a significant increase.

\subsubsection{Hardness}

On flash gold, due to its extreme thinness (around 12 $\mathrm{nm}$ ), the gold layer mechanical properties are neglected, even if the gold layer can influence thermal or chemical effects. Hardness of the different Nickel layer was measured with a nano indenter XP from MTS using a Berkovitch tetraedric indent at $115,12^{\circ}$.

Both electroless (NiP) and electrolytic Nickel have a hardness value above 500 Vickers, which is much harder than the standard Hard Gold plating used on the contact blades.

Due to this big difference in hardness between stationary surface and sliding contact, the roughness of the hardest partner (in our case the PCB) becomes a preponderant parameter for wear behavior.

\subsubsection{Roughness}

Traditional roughness parameters as $\mathrm{R}_{\mathrm{a}}$ and $\mathrm{R}_{\mathrm{q}}$ are seen to be concerned only with relative departures from the mean line in the vertical direction; they do not provide any information about the shape, slopes and sizes of the asperities or about the frequencies of their occurrence. It is possible to have the same $R_{a}$ and $R_{q}$ values for surfaces of widely different materials and profiles.

For example, on Fig. 5 are three surfaces that all have the same Ra, but you need no more than your eyes to know that they are quite different surfaces. In some applications they will perform very differently as well.

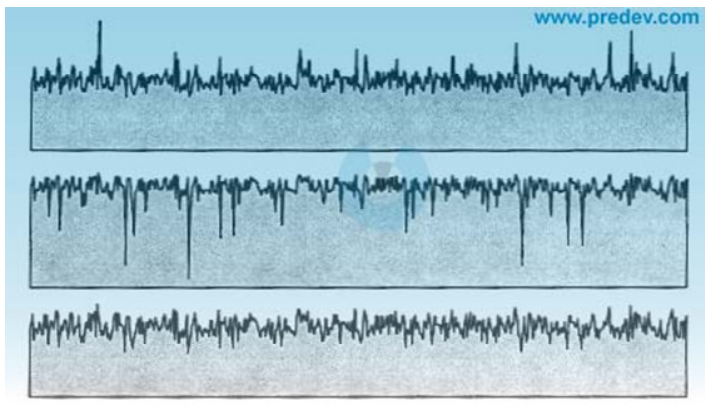

Figure 5 Example of surfaces providing same Ra value
To determine the "potential of wear" from our flash gold PCB surfaces we used the Abbott-Firestone curve (Fig. 6) to determine Rk, Rvk and Rpk and correlate those values with wear stage measurements on the sliding blade during lifetime tests.

The roughness measurements were carried out with a STILL confocal microscope; equipped with a CHR 150 sensor with a depth of field of $300 \mu \mathrm{m}$. It is a coaxial point sensor applying the principle of color coding of the area of measurement.

The criterion for the wear stage that was used is the width of the wear trace on the sliding blade measured periodically during the lifetime.

The correlation between wear and roughness parameters is shown in Table 1. The data were measured on two different types of PCB (ENIG and flash gold) and are the average taken out of 6 measurement points on each type of board.

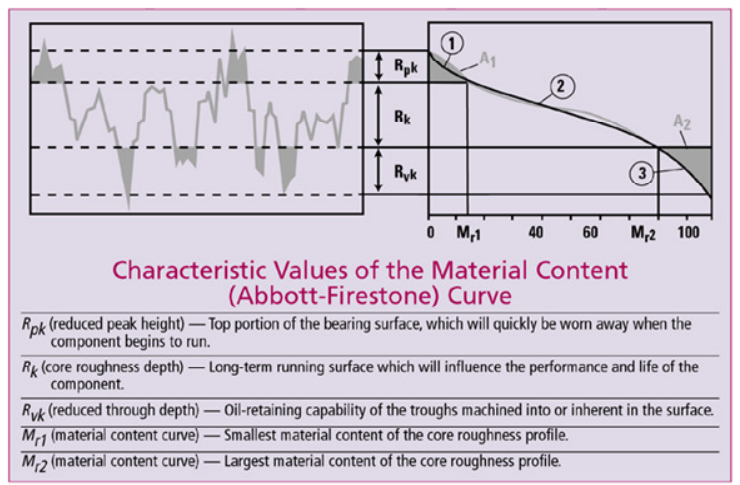

Figure 6 Abbott - Firestone curve definitions

\begin{tabular}{|c|c|c|}
\hline & $\begin{array}{c}\text { Pattern Plating } \\
(\text { Low abrasion) } \\
(\boldsymbol{\mu} \mathrm{m})\end{array}$ & $\begin{array}{c}\text { ENIG } \\
\text { High abrasion } \\
(\boldsymbol{\mu \mathrm { m }})\end{array}$ \\
\hline Rpk & 0.14 & 1.09 \\
\hline Rk & 0.58 & 1.75 \\
\hline Rvk & 0.16 & 0.74 \\
\hline
\end{tabular}

Table 1 (measurement results of 3 roughness parameters) 
On a PCB, the very thin metallic $(\mathrm{Cu}-\mathrm{Ni}-\mathrm{Au})$ layers reflect the laminate waviness (provided by the glass fiber weaving) a filtering of the measurement data is necessary to extract the roughness parameters $(\mathrm{Rk}, \mathrm{RpK}$ and Rvk). Fig. 7 shows an example of this filtering.

The first curve from top on Fig. 7 represents the raw data from measurement on the PCB Gold surface with the confocal microscope.

The second curve provides the waviness of the PCB laminate by filtering the data using a Gaussian filter with a cutoff length at $0,25 \mathrm{~mm}$

The third curve is the difference between the two previous ones in order to remove the waviness and take into consideration the micro roughness only and extract Rk, Rpk and Rvk parameters from the Abbott curve.

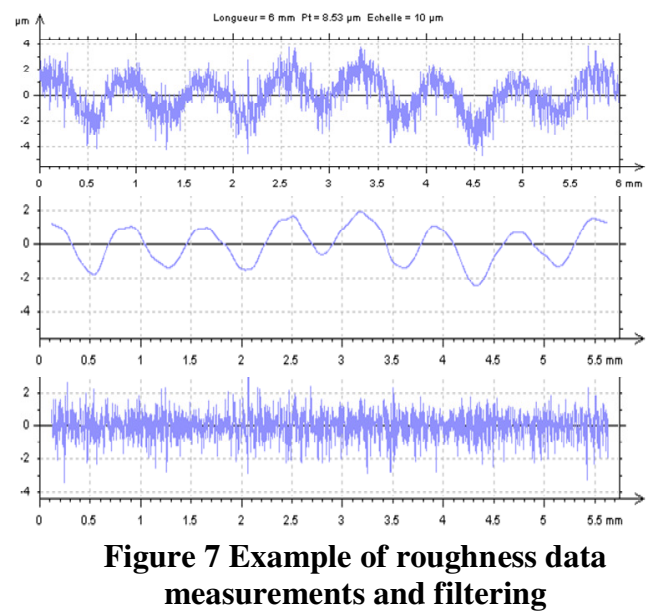

\subsubsection{Nickel structure}

The Nickel on Electroless Nickel Gold (ENIG) usually exhibits a columnar structure (Fig. 8) while electrodeposited Nickel grows in fine coats or strata (Fig. 9), providing a lower amount of wear debris and abrasion.

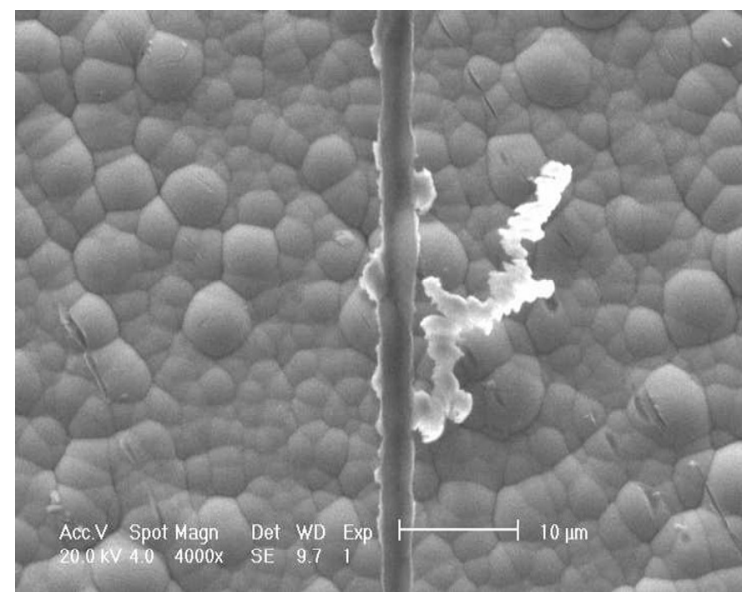

Figure 8 ENIG surface overview

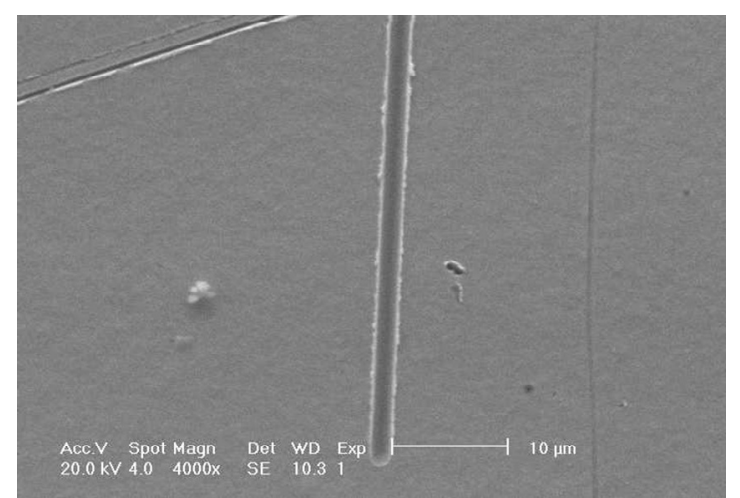

Figure 9 Electrolytic pattern plating surface overview

\subsubsection{PCB surface preparation}

To enhance the adhesion of liquid photoimageable soldermasks ${ }^{5}$ and dielectric materials to copper surfaces of PCB a surface preparation (micro-etching) is necessary. Micro Etchants are used as pre-processor for all PCB manufacturing processes for the purpose of oxide removal from surface, removal of pollutants and foreign matters. This micro-etching step has a major influence on the copper roughness and by consequence on the final contact surface roughness too.

Fig. 10 is providing an overview of copper surface after four different types of micro-etching; scrubbing, SPS type, Pumice brushing and organic CO-BRA BOND ${ }^{\circledR}$ SM.

The pictures show obvious differences in surface roughness for each type of micro-etching.

However, it is not possible to directly link a microetching type to a given roughness as the processing parameters used for this micro-etching have also an influence on the final result on roughness.. A deeper investigation would be necessary to demonstrate the influence of each micro-etching type and process parameters on the roughness.

\footnotetext{
${ }^{5}$ Soldermask is a protective layer of acrylic-epoxy (normally green) applied over bare copper lines. Known as Solder Mask Over Bare Copper (SMOBC).
} 


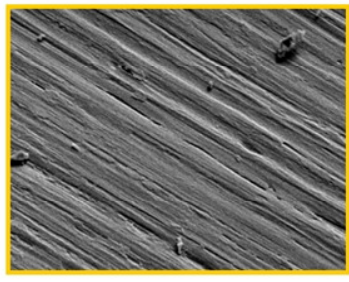

SCRUBBING

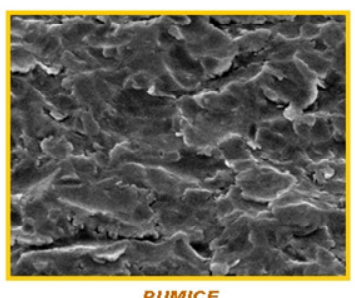

PUMICE

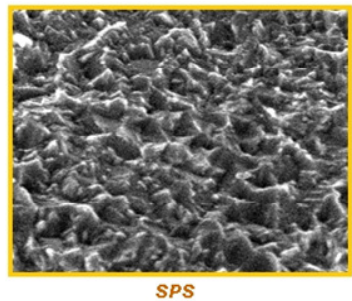

SPS

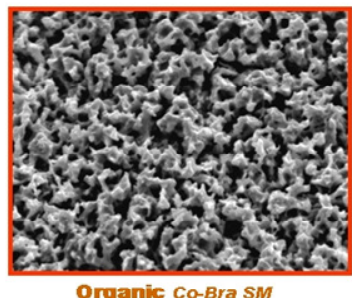

Organic Co-Bra SM
附圖一、各種不同前處理方法之電子顯微鏡圖片 (3500 倍)

Figure 10 Copper surfaces overview after micro-ecthing

\section{Conclusion}

The results provided by the lifetime experiments, PCB surface and material analysis conducted in this study show that key physical characteristics on the product like hardness, roughness, brittleness are strongly dependent on process parameters like surface preparation (microeching), chemicals used for the layer deposit but also on the process type (electrolytic versus galvanic) in case of gold plating. Of course the key process parameters like time, current density are of major influence, but were not taken into account here because considered as under control.

Among the three types of PCB plating that has been studied, electrolytic pattern plating provides the most interesting properties in term of roughness. It is mainly linked to the fact that PCB surface preparation prior photoresist generates lower roughness in comparison to brushing used prior solder mask on ENIG process. In other words the process steps sequence strongly influence the final result. In addition, some shiny and wetting agents are added in the nickel bath, providing very smooth and shiny surface.

Electrolytic Nickel layer usually grow as an addition of several horizontal layers (strata's), while ENIG plating provides a columnar growth of the Nickel layer.

- Hard Gold plating with a $2 \mu \mathrm{m}$ thickness is still the reference for sliding contact applications on PCB, nevertheless flash gold can be used as contact interface with some restrictions and great care about the surface topography when the switched electronic system allows some contact resistance variations up to a few Ohms (those variations were not quantified in detail here and are part of another study).
- $\quad$ PCB surface roughness is the key driver on wear behaviour for flash gold plating as the Nickel under layer is the preponderant factor.

- As the gold is porous, usage of specific protective grease is necessary to prevent oxidization of the Nickel layer trough the pores (especially pitting corrosion).

- The PCB must be chosen in order to ensure low abrasion; the selection can be done with Rpk, $\mathrm{Rvk}$ and Rk parameters. Preference is given to electrolytic Nickel and Gold deposits however this process needs some adjustments to avoid too high porosity.

- Grease will improve wear only if the surface roughness of hardest contact surface is below a certain value, otherwise grease could even accelerate the wear out of the surface.

\section{References}

1 L. Féchant, Le contact éléctrique, Phénomènes physiques et matériaux. (Hermès, Paris, 1996)

2 L. Féchant, Le contact éléctrique, l'appareillage de connexion. (Hermès, Paris, 1995)

3 R. Holm, ELECTRIC CONTACTS, 4th edition. (Springer-Verlag, New York, 1967)

4 M. Antler, in proceedings of the 18th Holm seminar on Electric Contact Phenomena, Chicago, 1972

5 M. Kishimoto, M. Ishino, M. Tanaka, S. Mitani, in proceedings of Holm Conference on Electrical Contacts, Chicago, 1978

6 Ji-gao Zhang, Ping $\mathrm{Yu}$, in proceedings of the 15th International Conference on Electical Contacts, Montreal, 1990

7 Seiki Harada, Kunio Mano, in proceedings of the 4th International Research Symposium on Electrical Contact Phenomena, Swansea1968

8 S. M. Garte, A. Solomon, in proceedings of the 18th Holm Seminar on Electric Contact Phenomena, Chicago, 1972

9 M. D. Bryant, in proceedings of the 36th IEEE Holm Conference on Electrical contacts, and the 15th International Conference on Electical Contacts, Montreal, 1990 